\title{
EMPHASIS-HF links eplerenone with reduced risk of new-onset AF
}

"Whether or not atrial fibrillation (AF) is an independent predictor of outcome in heart failure (HF)," comment the EMPHASIS-HF investigators, "its occurrence is commonly associated with symptom deterioration ... Consequently, AF is best avoided, if possible." A prospective analysis of EMPHASIS-HF has demonstrated that the mineralocorticoidreceptor antagonist eplerenone is associated with reduced incidence of newonset AF in the setting of mild systolic HF.

The EMPHASIS-HF investigators assessed patients with mild systolic HF both with $(n=943)$ and without $(n=1,794)$ AF or atrial flutter (AFF) at baseline. In the patients without AFF, eplerenone was associated with a reduced rate of new-onset AF during follow-up (median 21 months; $2.7 \%$ vs $4.5 \%$; HR $0.58,95 \%$ CI $0.35-0.96$, $P=0.034)$. A trend remained when the data was adjusted for covariates (HR 0.71, 95\% CI 0.49-1.05, $P=0.087$ ).
The effect of eplerenone on first occurrence of cardiovascular death or hospitalization for HF (the primary end point of EMPHASIS-HF) did not differ between patients with (HR 0.60, 95\% CI 0.46-0.79) and without (HR 0.70, 95\% CI 0.57-0.85) AFF at baseline ( $P$ for interaction $=0.411$ ).

Few treatments are proven to prevent new-onset AF in patients with HF.

Therefore, the news that eplerenone (added to recommended therapy) was associated with reduced incidence of new-onset AF in the patients assessed in EMPHASIS-HF is a welcome addition to the literature.

Bryony M. Mearns

Original article Swedberg, K. et al. Eplerenone and atrial fibrillation in mild systolic heart failure: results from the EMPHASIS-HF (Eplerenone in Mild Patients Hospitalization And Survlval Study in Heart Failure) study. J. Am. Coll. Cardiol. 59, 1598-1603 (2012) 